Brit. J. industr. Med., 1954, 11, 20.

\title{
SICKNESS ABSENCE BEFORE THE FIRST CLINICAL EPISODE OF CORONARY HEART DISEASE
}

\author{
BY \\ J. A. HEADY, J. N. MORRIS, F. J. LLOYD, and P. A. B. RAFFLE \\ From the Social Medicine Research Unit, Medical Research Council, and the London Transport Executive
}

(RECEIVED FOR PUBLICATION AUGUST 16, 1953)

There is a common belief that coronary (ischaemic) heart disease strikes healthy people without warning, and that it is related to personality (Dunbar, 1948); for example, the over-conscientious or the ambitious man. For these reasons, and in order to look for possible indications of future coronary disease, we took the opportunity while working with the records of London Transport Executive employees (Morris, Heady, Raffle, Roberts, and Parks, 1953) to compare the previous sickness experience of men suffering from a first clinical episode of coronary heart disease with the experience of other men chosen as controls. The idea was to make a preliminary examination, using data which would be sufficient to demonstrate a striking difference, though possibly not numerous enough to show a small one. With the material and methods at our disposal we felt that only a large difference would be worth following up.

\section{Material and Methods}

The investigation was restricted to drivers and male conductors of the central (red) buses aged between 44 and 64 inclusive, of whom there were approximately 16,000 in 1949 . The plan was to choose four " controls" for each " case". The "cases", as said, comprised all the men in the investigation who had a first clinical attack of coronary heart disease in 1949, whatever clinical form this took, whether as angina pectoris or as a "coronary thrombosis" (myocardial infarction). The controls were to be men without any record of coronary heart disease : some might be suffering at the time or have suffered in the past from other form of illness, but in practice the great majority would not be sick men. All cases and controls were on the "active list" of employees at the date on which the onset of the coronary episode brought men into the inquiry.

As the population from which the controls were drawn was so large, we were able to take account of five factors which might otherwise have biased the comparisons. These factors, for which cases and controls were matched, were : (1) Sex : the investigation was restricted to males only. (2) Age : the cases and controls were born in the same year. (3) Occupation: drivers were compared with drivers, and conductors with conductors. (4) Length of service with London Transport or the transport undertakings which preceded it: the cases and controls started service in the same year. (5) Group of garages : in 1949 the garages in the central area of London (which actually includes some of the suburbs) were grouped in three divisions. Cases and controls were drawn from the same division.

Finding the Controls.-A Hollerith punched card was available for each of the drivers and conductors from whom the controls were drawn. The cards (which included details of the five factors mentioned above) were sorted into batches representing drivers and conductors separately for each of the three divisions, making six batches in all. Cards in each of these batches were next sorted according to the last two figures only of the five-figure badge number* and so placed in virtually random order. The cards were then sorted into years of birth and years of entry to service, and lists were made of the cards in each sub-category so formed. The cases were similarly sorted and listed by division, occupation, year of birth, and year of entry to service.

Next, a clerk took the first man on the list of cases and looked through the list of possible controls until he found the first four men in the same occupation and geographical division with the same year of birth and year of entry to service. If it was not possible to select four controls with these characteristics the process was repeated for years of birth, and/or years of entry, which differed by one from the index year. No further substitution was

\footnotetext{
* The five-figure badge number is the serial number of the public service vehicle licence issued individually to the driver or conductor by the metropolitan police.
} 
permitted. In all, 137 controls were listed for 36 cases. A further scrutiny of the data revealed that a few cases had changed their occupation from conductor to driver, or vice versa. These cases were excluded, together with all their controls. Any controls who had changed their occupations were also discarded. This left 31 cases and 101 controls matched for the original five factors together, now, with a sixth-length of service in a particular occupation.

The Record of Sickness. - The individual staff record for each of these men was available and included details of employment and all absence due to sickness or accident experienced by the man concerned (Spratling and Lloyd, 1951). The record of absences also included annual and other leave thus making it possible to tell in which year the record actually started. This was not always the year of entry to the service ; but cases and controls were compared only for the period where the recording was complete. This period averaged 22 years. The end-point of the period of comparison for each control was the date of the corresponding case's first absence from work for coronary heart disease. We allowed for gaps in the records during war service by an arbitrary method; only 12 individuals were affected, four cases and eight controls. Length of absence is recorded in days, including the first day of absence but not the day of return, and we made no attempt to exclude Sundays, or bank holidays, or rest days which fell within the period of absence. We treated absences with no record of an end date as if they were for a single day. This again was an arbitrary procedure, justified by internal evidence and by the experience of the administrative staff. In any event very few absences were affected and both cases and controls were treated alike.

Because we included in our analysis only absences recorded as due to sickness or accident, "special" leave (e.g. for compassionate reasons) and absences without leave were excluded. It is possible that some short absences of one or two days, recorded as absence without leave, may have been due to sickness, or vice versa. A check made for the years 1951 and 1952 showed that the total number of days of absence without leave for drivers and conductors averaged only about one twentieth of the number of days of absence due to sickness. Pre-war records are not available but it is understood that there was even less absence without leave before the war. Not only is the extent of the absence without leave relatively unimportant compared with sickness absence, but there is no reason to believe that cases and controls differ in this respect.

We made little use of the recorded diagnosis of the cause of absence, because of the small numbers in the trial, frequent vagueness of recorded causes, and occasional omissions. The diagnosis was, however, used to separate absences due to injury ; and the records were also scrutinized for evidence of hypertension, diabetes, and other conditions possibly related to coronary heart disease.

We examined the individual staff records for both sickness absence and absence due to injury in two only out of the three divisions of garages, the numbers available being 23 cases and 77 controls100 men in all. These 100 men represent, in total, 2,195 years of experience and they were absent from work on account of sickness or accident 1,089 times for a total of 21,949 days. As it happens, therefore, each man was absent, on an average, about 11 times, and lost on the average 10 days each year, (including, as mentioned earlier, Sundays, public holidays, and rest days if they fell in the period of absence). We examined the records of the third division of garages for injuries only. Injuries are therefore dealt with separately, the number of men concerned being 132-all the 31 cases and 101 controls.

Classification of Absences.-We have classified absences according to their length as follows : "Short" absences (three days or less), "medium" absences (4-13 days inclusive), " medium long" absences (14-60 days inclusive), and "long" absences (61 days or more). In addition, as stated, we analysed separately absences due to injury, where the cause, as recorded, was traumatic. Within all these categories, for absences due to sickness, we compared the cases and controls according to both $(a)$ the number of absences and (b) the total number of days of absence. For absences due to injury, we considered only the number of absences. In all the comparisons the main purpose, which was aided by the design of the trial, was to compare the history of the cases and controls, excluding as many confounding factors as possible. The factors excluded were of course those for which the cases and controls were matched : importantly sex, age, and length of service in a particular job.

\section{Results}

The results for the cases and the controls are compared in Tables 1 and 2.

Number of Absences.-Table 1 deals with the number of times the "average man" in each 
TABLE 1

PREVIOUS SICKNESS ABSENCE OF MEN WITH FIRST CLINICAL EPISODES OF CORONARY HEART DISEASE COMPARED WITH CONTROLS

\begin{tabular}{|c|c|c|c|c|}
\hline \multirow[b]{2}{*}{$\begin{array}{l}\text { Type of } \\
\text { Absence }\end{array}$} & \multicolumn{2}{|c|}{$\begin{array}{l}\text { Average Number of } \\
\text { Absences per Man }\end{array}$} & \multicolumn{2}{|c|}{$\begin{array}{l}\text { Average Number of } \\
\text { Days Absent per Man }\end{array}$} \\
\hline & $\begin{array}{c}23 \text { Men } \\
\text { with } \\
\text { Coronary } \\
\text { Heart } \\
\text { Disease }\end{array}$ & $\begin{array}{c}77 \\
\text { Controls }\end{array}$ & $\begin{array}{c}23 \text { Men } \\
\text { with } \\
\text { Coronary } \\
\text { Heart } \\
\text { Disease }\end{array}$ & $\begin{array}{c}77 \\
\text { Controls }\end{array}$ \\
\hline $\begin{array}{l}\text { Short } \\
\text { 1-3 days inclusive }\end{array}$ & $\begin{array}{c}2 \cdot 1 \\
( \pm 0 \cdot 64)\end{array}$ & $\begin{array}{c}1 \cdot 5 \\
( \pm 0 \cdot 21)\end{array}$ & $\begin{array}{c}3 \\
( \pm 0 \cdot 8)\end{array}$ & $\begin{array}{c}2 \\
( \pm 0 \cdot 3)\end{array}$ \\
\hline $\begin{array}{c}\text { Medium } \\
4-13 \text { days inclusive }\end{array}$ & $\begin{array}{c}4 \cdot 0 \\
( \pm 0 \cdot 83)\end{array}$ & $\begin{array}{c}4 \cdot 0 \\
( \pm 0 \cdot 43)\end{array}$ & $\begin{array}{c}38 \\
( \pm 8 \cdot 1)\end{array}$ & $\begin{array}{c}35 \\
( \pm 3 \cdot 5)\end{array}$ \\
\hline $\begin{array}{r}\text { Medium long } \\
\text { 14-60 days inclusive }\end{array}$ & $\begin{array}{c}5 \cdot 3 \\
( \pm 0 \cdot 97)\end{array}$ & $\begin{array}{l}3.9 \\
( \pm 0.46)\end{array}$ & $\begin{array}{c}131 \\
( \pm 23 \cdot 8)\end{array}$ & $\begin{array}{c}93 \\
( \pm 10 \cdot 7)\end{array}$ \\
\hline $\begin{array}{l}\text { Long } \\
61 \text { days or more .. }\end{array}$ & $\begin{array}{c}\mathbf{0 \cdot 8} \\
( \pm \mathbf{0} \cdot \mathbf{2 7})\end{array}$ & $\begin{array}{c}0.6 \\
( \pm 0 \cdot 12)\end{array}$ & $\begin{array}{l}76 \\
( \pm 27 \cdot 2)\end{array}$ & $\begin{array}{c}65 \\
( \pm 14 \cdot 8)\end{array}$ \\
\hline All absences & $\begin{array}{c}12 \cdot 3 \\
( \pm 1 \cdot 75)\end{array}$ & $\begin{array}{c}10 \cdot 1 \\
( \pm 0 \cdot 75)\end{array}$ & $\begin{array}{c}248 \\
( \pm 44 \cdot 9)\end{array}$ & $\begin{array}{c}195 \\
( \pm 20 \cdot 8)\end{array}$ \\
\hline
\end{tabular}

The first clinical episode of coronary heart disease occurred in 1949. The previous experience of absence goes back as far as the records allow, on an average, 22 years. The men were aged 44-64 in 1949. There were not always the same number of controls for each man with coronary heart disease ; the averages presented for the controls are therefore averages of the means for each group of controls.

The figures in brackets preceded by the \pm sign are the standard errors of the averages shown above them. No individual difference is significant at the $5 \%$ level. In addition, the analysis of variance was used to test the differences for all absences, for "short " absences, used to test the differences for all absences, for " short" absences, for all absences other than "short," for "long" absences, and for absences and the number of days absent, except that for shor absences and absences due to injury there was no such analysis for the number of days absent. The test which allows for differences between drivers and conductors, and eliminates from the comparison the other factors used in the matching process, showed no significant difference between men with coronary heart disease and controls.

group was absent during the period of comparison, and breaks this number down into the different types of absence, classified as we have just described according to the length of the absence.

Number of Days Absent.-Table 1 shows also the number of days the average man in each group lost through sickness during the period of comparison, and breaks this number down in a similar way.

The men with coronary heart disease show an excess of two absences and just over 50 days of absence per man in a mean experience of 22 years. They have an excess in each type of absence (except in absences of four to 13 days when they are equal) but it will be noted that the standard errors of the averages are large in comparison with these differences and no difference is significant at the conventional $5 \%$ level.

Differences in Distribution of Absences.-It is possible that the averages shown above are obscuring important points. Although the averages are not significantly different there might, for instance, be considerably more variation in the number of absences amongst the controls than amongst the cases. This might result, for example, in a much higher proportion of men with no absences and with many absences in the cases, but more with a moderate number of absences in the controls. Table 2 shows that, while there may be differences of this sort, consistent with the general pattern of more absence amongst the cases than among the controls, such differences cannot be conclusively demonstrated because none of those shown in the Table are significant at the $5 \%$ level. It is possible that real differences exist, but as before, are too small to be demonstrable in a sample of this size.

These three measures-the number of absences, the number of days absent, and the distribution of the number of absences-summarize most of the information which can be extracted from the present type of analysis.

TABLE 2

PREVIOUS SICKNESS ABSENCE OF MEN WITH FIRST CLINICAL EPISODES OF CORONARY HEART DISEASE COMPARED WITH CONTROLS

\begin{tabular}{|c|c|c|}
\hline Percentage of Men with & $\begin{array}{l}23 \text { Men with } \\
\text { Coronary } \\
\text { Heart Disease }\end{array}$ & $\begin{array}{c}\text { Among } 77 \\
\text { Controls }\end{array}$ \\
\hline Less than 5 absences of all durations & $17 \%$ & $26 \%$ \\
\hline More than $20, \quad, \quad, \quad$, & 22 & 12 \\
\hline No " short" absences .. & 43 & 36 \\
\hline No "long" absences $\quad$. & 52 & 60 \\
\hline
\end{tabular}

None of these differences is significant at the $5 \%$ level. See also notes to Table 1 .

Absences Due to Injury.-The mean number of absences per man due to injury during the whole period of observation was 1.0 among the cases and 0.7 among the controls. This difference also, although in the same direction as before, is not significant at the $5 \%$ level.

Other Comparisons.-There were no significant differences between drivers and conductors, either amongst the cases or amongst the controls, and they are therefore not shown separately in the table. Similarly, there were no differences between divisions of garages. The number of absences increased, of course, with age and length of service.

\section{Comment}

There is no striking difference between the experience of cases and controls, though there may possibly be small differences.

A negative result of this sort-the absence of a significant numerical difference or of a difference in pattern-is difficult to interpret. To have found a 
difference would have been interesting ; to demonstrate that there is no difference would be at least as interesting. But unfortunately, a limited trial such as this cannot possibly prove the absence of a difference. It may be that there is a difference, but in other characteristics than those we have examined, for instance, in connexion with the diagnosis of the cause of sickness absence, or between the previous experience of cases who died " suddenly" in their first clinical attack of coronary heart disease and those who did not. To test this last possibility would require far larger numbers than we have at our disposal. We cannot think of other useful ways in which these sickness data could have been analysed in quantitative terms, but that does not mean that there are none. Moreover, it is possible that there is a difference, even in the characteristics we have examined, which is too small to be shown in the limited experience presented. In this connexion it is important that the differences, though not significant, show a consistent slight excess of absence amongst the cases. But it should not be forgotten that the three measures, "number of absences per man", " number of days absent per man" (Table 1), and the distribution of absences (Table 2 ), are in a very real sense only different ways of presenting the same material. If there were a real difference in, say, the number of absences, it would almost certainly show up also in the number of days absent and in the "distribution" table. In other words, these three pieces of evidence must not be accepted as independent. Further, we are dealing throughout with the same 100 men and it is quite possible that, for instance, a man who is more likely than his fellows to have absences of, say, 14 to 60 days is also more likely to have absences of four to 13 days, or for more than 60 days. The choice of the number of days of absence for the analysis of different types of absence is quite arbitrary. We may be dealing by chance with a slightly more sickly group of men in the cases than in the controls, because the controls, as we have shown, were drawn as nearly as possible at random. Even if we assume that the numbers of absences of different lengths are independent, and calculate the probability that differences of the observed sizes will all fall the same way, the result is still quite likely to have occurred by chance, the calculated probability of this chance being greater than the conventional $5 \%$. Moreover, the degree of apparent consistency seen in Tables 1 and 2 in the difference between cases and controls disappears when drivers and conductors are analysed separately.

There is another aspect to these figures. Detailed analysis of the data (which we have not the space to show) indicates very clearly that the variation among individual men is consistently greater than between the two groups, cases and controls. Individual differences are in fact very great. The conventional measure of this variability, the standard deviation of the number of absences of all types (as opposed to the standard error of the average shown in Table 1) amongst cases and controls is 7.4.

The important point is that, even if there is a real group difference (cases as against controls) it cannot be large compared with the individual differences. It can be shown, using the numbers in Table 1, that the difference between the mean number of absences per man in the two groups is unlikely to be greater than four in 22 years of comparison. For this reason the approach through the study of sickness absence is unlikely to have any prognostic value in picking out men who are particularly susceptible to coronary heart disease.*

Since the results give no indication of a striking difference, which alone would be interesting with this type of material, no further extension of the present pilot study is felt to be justified. The small differences shown in this paper would only have been significant at the $5 \%$ level if there had been four times as many cases and controls.

\section{Conclusion}

There is no suggestion that there is any important difference in the health history, as here examined, of the cases and the controls, in particular of a difference which might be associated with a characteristic type of personality. To some extent, however, the result can be looked on as support for the idea mentioned earlier that coronary heart disease strikes suddenly and without warning, though not that coronary heart disease selects particularly healthy men. Taken at their face value, the present observations suggest that the previous sickness absence of cases of coronary heart disease presenting for the first time is, on the average, similar to that of any group of comparable men still in active work. There is little in their previous sickness record to distinguish the coronary cases from their normal fellows who do not suffer from coronary heart disease. If anything there is a slight indication that men with coronary heart disease have more sickness than these " normals", rather than less. Amongst any such " normal" group there will be people with good and bad health records, including the man with an absolutely clear record. This variation in health record is also characteristic of men who

\footnotetext{
* An examination of the records of the cases shows no absence at all before the first clinical attack of coronary heart disease for related
conditions such as hypertension and diabetes, so that the slight overall conditions such as hypertension and diabetes, so that the sligh
excess found in the cases cannot be explained in this way.
} 
eventually get coronary heart disease, and is much greater in the present material than the variation between men who are going to get the disease and those who are not. It would be interesting to carry out a similar trial for men suffering from other common diseases of middle-age, duodenal ulcer and cancer, for instance. Many such problems of the previous history of men with different complaints, or of the association and dissociation of various diseases, could be investigated from the statistics collected day by day in industry where, moreover, the difficult problem of the selection of adequate " controls" may often be readily resolved.

\section{Summary}

The sickness absence experience before the onset of the first clinical episode of coronary heart disease in a group of drivers and male conductors of the London Transport Executive is compared with that of a group of controls matched for sex, age, job, and length of service. No significant differences at the $5 \%$ level are found between the two groups, either in the number of absences, the total number of days of absence, or in the distribution of different types of absences.

We are very grateful to Mr. F. H. Spratling, Dr. L. G. Norman, Mr. K. G. Murden, and Mr. C. J. Cornwall of the London Transport Executive for advice and helpful criticism; to Mr. C. F. Stevens of the Social Medicine Research Unit for help with the mathematical analysis ; and to Miss C. Davies, also of the Unit, for extracting the data from the original records.

\section{REFERENCES}

Dunbar, F. (1948). Psychosomatic Diagnosis. London. Morris, J. N., Heady, J. A., Raffle, P. A. B., Roberts, C. G., and Parks, J. W. (1953). Lancet. 1054, 1111.

Spratling, F. H., and Lloyd, F. J. (1951). Journal of the Institute of Actuaries, 77, 196. 